\title{
Surgical Treatment of Post-Mastoplasty Impound Improvement Deformities
}

\author{
Tamayo Carbon AM1, Vila Garcia $\mathrm{E}^{2 *}$, Orozco Jaramillo $\mathrm{MA}^{3}$, Ramos \\ Amezquita $\mathrm{LM}^{4}$ and Posada Ruiz $\mathrm{DA}^{5}$ \\ ${ }^{1}$ Specialist of II Degree in Plastic Surgery and Caumatology, Hermanos Ameijeiras \\ Hospital, Cuba
}

${ }^{2}$ Specialist I Degree of General Surgery, Hermanos Ameijeiras Hospital, Cuba

\section{Conceptual Paper}

Volume 3 Special Issue 2

Received Date: July 19, 2019

Published Date: September 16, 2019

DOI: $10.23880 /$ ijtps-16000S2-008

${ }^{3}$ Resident of the second year of Plastic Surgery and Caumatology, Hermanos Ameijeiras Hospital, Cuba

${ }^{4}$ Resident of first year of Plastic Surgery and Caumatology, Hermanos Ameijeiras Hospital, Cuba

${ }^{5}$ Resident of the second year of Plastic Surgery and Caumatology, Hermanos Ameijeiras Hospital, Cuba

*Corresponding author: Prof Eyleen Vila Garcia, Services of Plastic Surgery and Caumatology and General Surgery, Surgical Hospital Hermanos Ameijeiras, Havana City, Cuba, Tel: 53232327; Email: hielenvg@infomed.sld.cu

\footnotetext{
Abstract

Introduction: Increasing the demand for mastoplasty increases the risk of developing complications and deformities after implant placement. Objective: To evaluate the results of surgical treatment of late post-mastoplasty augmentation deformities.

Method: A longitudinal and prospective descriptive study was carried out with 31 operated patients of mastoplasty of increase coming from other hospitals with delayed deformities that attended the surgery of Plastic Surgery from January 2014 to December 2018.

Results: Different surgical procedures were used for breast reconstruction and the most used was the change of the implant followed by the change of plane and mammary pexia. The most frequent complications were breast ptosis, followed by capsular contracture and unsightly scar. The results of the secondary mastoplasties were good, the majority with few complications.
}

Conclusions: We did not find a single surgical procedure that could be applicable and reproducible for all late postmastoplasty augmentation deformities.

Keywords: Augmentation mastoplasty; Breast implants; Mammary deformities

\section{Introduction}

Breast development is one of the most outstanding characteristics of female morphology. Throughout history, the breast has been a cause of attraction, a symbol of sexuality, beauty, eroticism and expression of femininity. Its shape, size, characteristics and perception have been intimately linked to historical, cultural and 


\section{International Journal of Transplantation \& Plastic Surgery}

personal factors, creating icons and ideals of beauty that are continuously transformed $[1,2]$.

The augmentation mastoplasty is a surgical procedure through which the size of the breasts is increased by the insertion of prostheses of different characteristics and in different anatomical planes [3,4]. Technically it is a procedure that enlarges and improves the shape of the mom. Its indication varies from simple aesthetic desire to post-mastectomy reconstruction, creating a more aesthetic body contour, which directly impacts on the patient's self-image and self-esteem [1,2,4-6].

Mammary prostheses are alloplastic materials that are characterized by biological inertia due to their hydrophobic properties $[4,7,8]$. They can be constituted by different fillings (saline solution and silicone gel), all with an external cover made of silicone elastomer, with advantages and disadvantages, as well as indications and contraindications [6,8-10]. They have different surfaces that go from the smooth to the textured, varied profiles: (super high, high, medium and low), different shapes and sizes $[3,4,6,11]$.

Those with a smooth surface have the advantages that they are softer to the touch, by not adhering to the tissues they follow the body postures better, they can be introduced by smaller incisions, they slide easily, and they have a lower incidence of seroma. However, they can be moved and rotated inside the pocket, and if they are placed in a subglandular position they have a high incidence of capsular contracture $(30 \%)[4,6]$. Textured surfaces arise with the intention of decreasing the incidence of capsular contracture, adhere to the tissues and are difficult to rotate or move, but have a higher incidence of seroma and a larger incision is needed to introduce them $[12,13]$.

Regarding the position or plane of placement of the implant, it can be submuscular, subglandular or subfascial, and various are the approaches: submammary groove, periareolar that can be total or in upper or lower region of the areola, Vertical, inverted T, closure in J or L, and the axillary or umbilical pathways with special instrument requirements for this purpose. Joint techniques have also been described, such as performing an abdominal dermolipectomy and through previous scars $[4,11,14]$.

The postoperative care of the mastoplasty of increase are essential for an adequate and satisfactory evolution of the patient and vary from the placement of vacuum drainage, analgesics and muscle relaxants, the use of bandage or adjuster and thoracic stabilizer to the rest of physical activity that uses The pectoral muscle, physiotherapy, massage and lymphatic drainage by professionals after ten days of the procedure $[6,11,15,16]$.

Cosmetic surgery of the breast has risks and complications. Early complications such as infection, seroma, hematoma, extrusion of the implants may appear; and delayed as an inesthetic scar, asymmetries, capsular contracture, breast ptosis and superficialization, displacement or rupture of the implant; resulting in postsurgical breast deformity $[4,6,7,17]$.

The risk factors of late breast deformity can be grouped into: the patient's own, the breast implant, the surgical procedure or the inadequate treatment of early complications $[6,8,18-20]$.

The patient's dependent factors may be due to inadequate care and follow-up of the postoperative indications. The dependents of the breast implant are based on the characteristics of the selected prosthesis and those related to the surgical procedure include the implant placement plane, the approach or the malpractice. It may also be due to inadequate treatment of immediate complications $[4,11,14]$.

The increase in the demand for mastoplasty increases the risk of developing complications and the number of patients who come for deformity. There is a protocol for the treatment of immediate complications, however, for the correction of late deformities there is no preestablished algorithm. There are multiple factors and causes that give rise to the appearance of these deformities and therefore the surgical treatment options that must be individualized to each patient and each breast are varied. Soft tissue treatment options with mastopexy, capsulotomy, partial or total capsulectomy, implant change, position and / or plane, implant removal, or the combination of these have been described [14,2124].

Because it is a growing problem in the community with scarce current literature, the motivation for this study arises with the aim of evaluating the results of the surgical treatment of late post-mastoplasty augmentation deformities.

\section{Method}

A longitudinal and prospective descriptive study was carried out with 31 operated patients of mastoplasty of increase from other hospitals with late deformities with 


\section{International Journal of Transplantation \& Plastic Surgery}

indication of surgical treatment who attended the consultation of mammary dysmorphisms of the Plastic Surgery and Caumatology service of the Clinical Surgical Hospital "Hermanos Ameijeiras" in the period from January 2014 to December 2018. Patients with chronic diseases decompensated or reconstructed due to cancer were excluded.

\section{First Consultation}

The patients are classified in the consultation according to the degree of mammary deformity, preoperative, preanesthetic check-up is indicated and the different options of surgical treatment are proposed. The risks and benefits of the procedure are explained to the patient, possible complications, doubts are clarified and the informed consent is signed.

If the patient is a candidate in exchange for a breast implant, the shape, surface, profile and volume of the implants are indicated, taking into account the biotype, the patient's wishes, the deformity and the volume of the breast. Regarding the volume of the implant, the minors were for patients with capsular contracture, reserving those of greater volume for patients with breast ptosis (due to subglandular implant or pregnancy), and / or desire of the patient (100cc on the initial volume of the implants). and up to $400 \mathrm{cc}$ as the total volume of the implant).

\section{Surgical Intervention}

Surgical intervention is defined individually based on the mammary deformity and the degree of tissue involvement. It is performed with hospitalized patients, regional or general anesthesia and treatment focused on soft tissues, capsule (capsulotomy, partial or total capsulectomy) to the implant (change of implant, position and / or plane), or the combination of these.

\section{Surgical Procedures}

Capsulotomy: Its objective is the weakening and loss of continuity of the periprosthetic capsule, offering greater distensibility and space to the prosthesis. Two types are described: closed and open; the closed technique is in disuse. The open technique requires opening the pocket and incisions in the capsule until obtaining the desired release, expandability and space; It was performed to treat grade I, II capsular contractures and mammary asymmetry.

Capsulectomy: The exeresis of the capsule partially or totally, allows the recreation of a pocket "virgin" which is the equivalent of a plane change, being very useful for cases with very thick and fibrous capsules, with a high degree of calcification or the presence of siliconomas. In patients with extensive or total capsulectomy, the use of drains is required [6,7].

Mastopexy: Surgical procedure through which breast ptosis is corrected, its objectives are the repositioning of the Areola-Nipple Complex (ANC), the exeresis of redundant skin, fix the breast to the thoracic bases and create a mammary cone aesthetically more attractive when not no change in volume is indicated. Due to the different degrees of ptosis there are mastopexy techniques described for their correction and the types of proposed closures are different (periareolar, vertical, L, J or inverted T) [5-7].

Change of position: The implant is repositioned in the same plane where it is. Indicated in patients with mammary asymmetry and with submuscular implant. Partial capsulectomy and capsulotomy are required to reach the symmetrical margins of the pockets, an adequate positioning and distribution of the breast.

Change of plane: Indicated in patients with superficialization of the prosthesis, subglandular postimplant ptosis and capsular contracture. The objective is to give more coverage to the implant, reposition the mammary cone and avoid the recurrence of complications.

Implant change: The breast implant is removed and a new one is implanted. It is indicated in patients who presented early complications such as infection and / or hematoma, in which they debuted with capsular contracture requiring another volume, in cases of implant rupture, ripling, folding or more than 10 years after the procedure.

Removal of the implant: Procedure by which the breast implant is removed due to the patient's desire or because of complications such as hematoma or seroma if it is accompanied by infection or are recurrent, capsular contracture and immunological rejection of the prosthesis.

\section{Pre-operative Planning}

It is performed with the patient sitting upright, facing forward and hands on the thighs. Taking into account the anatomical reference points, the midline is marked from the sternal fork to the navel, the mid clavicular point is located and a line is marked that extends to the submammary groove. Subsequently, the new pocket is defined taking into account the base of the breast implant, the birth of the breast, the submammary groove, the anterior parasternal and axillary line. The selection of the approach was determined by the existence of previous scars and excess tissue. Depending 


\section{International Journal of Transplantation \& Plastic Surgery}

on the degree of ptosis, the mastopexy technique was chosen, periareolar for ptosis up to $2 \mathrm{~cm}$, and in cases of moderate or severe ptosis, vertical closures were planned, in $\mathrm{L}$, in $\mathrm{J}$ or in inverted $\mathrm{T}$.

\section{Preoperative Indications}

Free diet until 18:00 and liquid until 6 hours before surgery, antibiotic prophylaxis is indicated with cefazolin $3 \mathrm{gr}$ ( $1 \mathrm{gr}$ pre, trans and postoperatively) and diazepam $5 \mathrm{mg}, 1$ tablet oral 22:00 hours.

\section{Intraoperative}

The surgical procedure is performed with general orotracheal anesthesia, asepsis and antisepsis with $10 \%$ iodopovidone solution or alcoholic hibitane, incision according to preoperative planning and dissection by planes to the capsule. Pocket opening through Capsulotomy and removal of the implant with subsequent cavity washing to eliminate waste; Depending on the degree of deformity, the indicated treatment is carried out (directed to the implant, the capsule, the plane and soft parts).

In all cases, breast implants are placed submuscularly; the manipulation of the implant is performed by a single surgeon, for the shortest possible time with previous washing of gloves, instruments and implants with $0.9 \%$ physiological solution; selected surgical technique is performed, rigorous hemostasis, drainage and closure by planes. Dressing is placed on surgical wound and occlusive.

\section{Postoperative Care}

In the immediate postoperative period, rest is indicated in the semi-fowler position, intravenous hydration, antibiotic prophylaxis, analgesia and symptomatic management. The first cure is performed the next day, by dry technique with alcohol, the surgical wound is occluded with sterile dressing, surgical adjuster and stabilizing band. If the patient recovers optimally and without complications, she is discharged the day after the surgical procedure with follow-up by external consultation until the withdrawal of points.

\section{Evaluation of the Aesthetic Results of Surgical Treatment}

Volumetric and longitudinal measurements were taken pre and postsurgically (1, 3 and 6 months) with frontal, profile and oblique photographs of both sides and symmetry between the two breasts bandage $[6,7,25,26]$.
The criteria evaluated were the measures:

1. Sternal fork - ANC (18 to $21 \mathrm{~cm}$ ).

2. I intermamilar (19 to $21 \mathrm{~cm}$ ).

3. ANC - Submammary furrow $(5$ to $7 \mathrm{~cm})$.

4. ANC - middle line ( 9 to $11 \mathrm{~cm})$.

5. Degree of ptosis (0 to $1 \mathrm{~cm}$ ).

6. Volume regarding the symmetry between the two breasts.

They were classified as excellent, good, fair or bad:

Excellent: When all the criteria are met. Good: When 4 or 5 of the criteria are reached.

Regular: When 2 or 3 of the criteria are reached.

Bad: None or only one of the 6 criteria is reached.

The data were summarized in absolute numbers and percentages. The proportions comparison test was performed using the program for epidemiological analysis of tabulated data EPIDAT, version 3.1. A significance level $\alpha=0.05$ was prefixed.

\section{Results}

Of 31 patients who presented a postoperative late postoperative unsatisfactory increase, the most frequent complication was breast ptosis (38.7\%), followed by capsular contracture and unsightly scar $(29 \%)$ and thirdly the superficialization of the implant $(19,4 \%)$ followed in a smaller proportion of the asymmetries of the ANC and the breast and finally the rupture of the implant (6.5\%) (Figure 1).

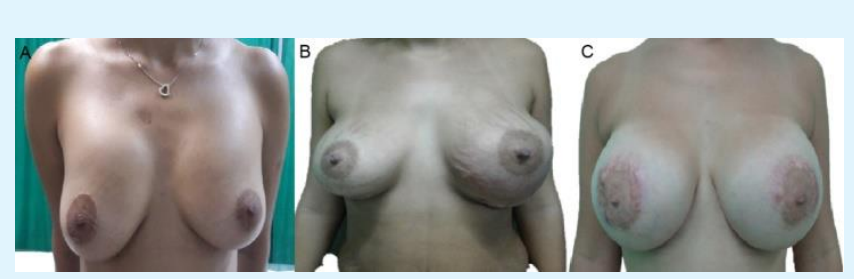

Figure 1: A: Post-implant ptosis.

B: Grade IV capsule contracture and left breast mastitis. C: Inaesthetic scars of bilateral ANC.

In the present investigation the factors related to the development of late postmastoplasty augmentation deformities are four main groups:

1. Referred by patients as a consequence of
complications. 2. Attributed to the patient (pregnancy (9.7\%).

3. Postoperative carelessness (6.5\%).

4. Inherent to the immune response (3.2\%). 


\section{International Journal of Transplantation \& Plastic Surgery}

Factors related to the technique are also described, taking into account the access route and the breast implant plane. $64.5 \%$ of the complications presented were found in patients with a subglandular implant and $35.5 \%$ in the submuscular plane, that were results significant $(p=0.04)$. According to the access route, it was observed that $48.4 \%$ of the cases were approached periareolarly, $45.2 \%$ by the submammary groove and only up to $3.2 \%$ in cases of $\mathrm{J}$ or inverted $\mathrm{T}$ approaches.

According to the characteristics of the breast implant, it was observed that implants of round shape and with silicone gel filling were found in all the patients; the textured surface was prevalent $(67.7 \%)$ on the smooth surface $(32.3 \%)$; the volume used ranged between 251 $300 \mathrm{cc}(32.3 \%)$, followed by volumes between 301-350cc (35.5\%), and 351-400cc (25.8\%) and less than 250cc and greater than $400 \mathrm{cc}$ in $3.2 \%$ of cases.

Different surgical procedures were used for breast reconstruction. The combination of different techniques was performed, the most used were the change of the implant followed by the change of plane and the mammary pexia (Table 1).

\begin{tabular}{|c|c|c|}
\hline Surgical procedures & Quantity & Percentage \\
\hline Implant Change & 25 & 80,6 \\
\hline Change of plane & 20 & 64,5 \\
\hline Pexia & 18 & 58,1 \\
\hline Capsulotomy & 5 & 16,1 \\
\hline Change of position & 4 & 12,9 \\
\hline Partial Capsulectomy & 3 & 9,7 \\
\hline Implant removal only & 1 & 3,2 \\
\hline $\begin{array}{c}\text { Source: Clinical } \\
\text { histories. }\end{array}$ & $\begin{array}{c}\text { Source: Clinical } \\
\text { histories. }\end{array}$ & \\
\hline
\end{tabular}

Table 1: Surgical procedures.

The evaluation of breast post-reconstruction results were: good $51.6 \%$, excellent $38.7 \%$, regular $6.5 \%$ and bad $3.2 \%$. The relationship between the most frequent complications and aesthetic results was evaluated and 12 patients presented post-implant ptosis, $50 \%$ showed excellent results and $41.7 \%$ good results, so $91.7 \%$ presented good to excellent results and this was significant $(\mathrm{p}<0.01)$. The capsular contracture were presented in 8 patients with good results in 7 patients and excellent in only one, which was also significant $(p<0.01)$. Given the superficialization of the implant or inesthetic scar, the result was good in $50 \%$ and $44.4 \%$, respectively, without statistical significance.
The relationship between the most frequent complications and the initial surgical technique was described, it was found that breast ptosis is associated with the access route by the submammary groove $(58.3 \%)$ and the subglandular position $(75 \%)$, in the latter case significantly $(p=0.04)$. The capsular contracture was related to the periareolar approach $(66.7 \%)$ and to the subglandular position (55.6\%), results that were not significant and $77.8 \%$ of the implants were textured surfaces.

\section{Discussion}

Breast augmentation surgery, like all surgical procedures, has risks and complications, which may be common to other surgical interventions or specific to implants. They can be early or late. The complication rates in general are not very high, the complication most often described in this procedure is capsular contracture, with an incidence of $8 \%$ to $30 \%$; followed by other complications such as hematoma, seroma, infection and unsightly scar with a frequency that ranges between $1 \%$ and $6 \%[6,11,14,17,27,28]$.

This study shows that late post-mastoplasty augmentation deformities are caused by one or several complications, so that in the same patient several factors can converge. The main deformities were breast ptosis, followed by capsular contracture, unsightly scar, and third, superficialization of the implant.

International literature reports capsular contracture as the main complication in $50 \%$ or more of patients. In implants filled with saline solution, capsular contracture grade III and IV was evident in 9\% at three years and 11 $16 \%$ at 7 years postoperated; and for implants filled with silicone gel capsule contracture grade III and IV of $8-13 \%$ at three years, followed by unattractive complications, implant misplacement, alteration in shape and residual ptosis $[7,28,29]$.

The results of capsular contracture were similar to the current literature on the subject, however residual ptosis is considered as a rare deformity, related to planning and surgical technique.

In another case study conducted by Blount and Cols, it was observed that the incidence of complications was poor positioning $(7.4 \%)$, rupture of the implant $(3.7 \%)$, capsular contracture grade III and IV (2.8 \%) and sequelae of healing (2.2\%), in decreasing order [29]. This work corresponds to the results of this study, the most frequent diagnosis being breast ptosis. 


\section{International Journal of Transplantation \& Plastic Surgery}

Most of the complications were related to the placement plane of the subglandular prosthesis, being present in the majority of them as the main complication breast ptosis, the superficialization of the implant and the unsightly scar, which is why the placement of breast prostheses is recommended for aesthetic purposes in the submuscular plane.

Three patients operated for augmentation mastoplasty were pregnant in the postoperative period. All presented complications in healing, position and a final result of post-implant ptosis with an unattractive scar.

The late mammary deformity of 2 patients was a result of poor treatment of early complications (hematoma and / or infection) with subsequent exposure of the implant, which caused mammary deformity, based on inesthetic scar, capsular contracture and superficialization of the implant (Figure 2).

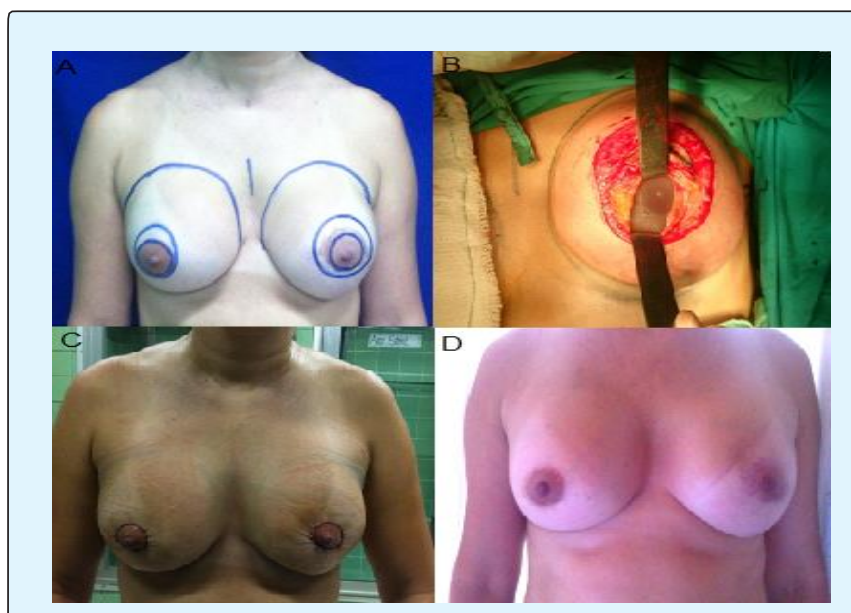

Figure 2: A: Deformity in the right breast and Asymmetry of persistent pain in the left breast.

B: Intraoperative: implant incorrectly placed inverted covered by periprosthetic capsule in subglandular plane.

C: Immediate postoperative breast reconstruction.

D: Late postoperative.

The best way to avoid early complications is prevention, with adequate preparation of the medical history, preoperative and psychological physical examination, the use of prophylactic antibiotic therapy and a detailed explanation of postoperative care.

In patients with breast ptosis related to the position of the subglandular implant, prosthesis was changed to a greater volume (up to $100 \mathrm{cc}$, with a maximum total volume of $400 \mathrm{cc}$ ), change of plane, to submuscular, and mastopexy in its Periareolar majority, correcting up to 2 $\mathrm{cm}$, obtaining a mostly good result, according to the satisfaction rating.

Mammary asymmetry is another complication that in the literature is associated with the placement of submuscular implants that project a high and asymmetrical upper contour, with abnormal movement in the face of muscle contraction. The asymmetry is delayed, it is observed over time and is associated with selfinflating implants filled with saline solution due to their deflation. The treatment of this deformity consists in removing the implants and changing the location plan. Suture or repair of the pectoral muscle and placement of new implants in subglandular or subfascial plane. In addition, it is associated with displacement of the implant early, which can occur due to inadequate adherence to postoperative care. It is observed in the first control, it can be corrected by placing it in the desired position by means of devices (stabilizing band and surgical adjuster) for several weeks. If the problem is not treated in time it will produce a mammary asymmetry, being necessary to correct it surgically $[6,11]$.

The mammary asymmetry in this study is presented in equal proportion for the submuscular and subglandular planes, associating this result more with the surgical technique in the creation of the pocket, and the lack of adherence to post-operative care such as the use of the adjuster, the stabilizer, performing physical exercises and inadequate physiotherapy.

If there was capsular contracture or mammary asymmetry, radial open capsulotomy or partial capsulectomy, never total, was performed to use the cover material capsule, since there was glandular and muscular hypotrophy. Women with grade III or IV capsular contracture according to the Baker scale are treated as treatment. Closed capsulotomy may increase capsular contracture, even in Baker grade I contractures. Several authors have described a high risk of recurrence in patients with closed capsulotomy. Additionally, a significant risk of rupture and malposition of the implant and hematoma with this technique. Due to the high recurrence and complication rates in closed capsulotomy, the Institute of Medicine of the National Academies of Science does not recommend closed capsulotomy to treat capsular contracture [28].

Open capsulotomy or capsulectomy is the treatment of choice for symptomatic capsular contracture. However, there is no consensus on the use of capsulotomy versus 


\section{International Journal of Transplantation \& Plastic Surgery}

capsulectomy. Although capsulectomy has had a lower rate of recurrence compared to capsulotomy, capsulectomy is a more difficult procedure and is more associated with complications [28].

Within the literature reviewed there are no absolute criteria for the performance of one or the other procedure; Due to this and the complexity and variety of causal diagnoses of the mammary deformity, each patient was given an individualized and personalized treatment.

No closed capsulotomy was performed in the study because of the risks that may appear, nor total capsulectomy because none of the patients presented active infection, calcification of the capsule and contractures were grade II. In the bibliography, numerous reports are described with the aim of preventing capsular contracture, among which they recommend minimizing the time of manipulation of the implants, using irrigation with antiseptic solutions, the use of electrocautery instead of blunt dissection, positioning the implants in the submuscular or flat plane and minimize the use of drainages. ${ }^{29}$ These principles were taken into account when performing most surgical procedures, to avoid complications and recurrences of capsular contracture.

The assessment of the aesthetic results was carried out objectively by comparing the measurements of the patients obtained 6 months after the reconstruction, in relation to those provided in the literature as the ideal measures; with a good result, for most of the cases treated. These results are not comparable, because there are no studies on this. In the work done on this topic, they show the procedures performed, but they do not evaluate the final result in a group of patients. The main late deformities post-mastoplasty augmentation, are breast ptosis, capsular contracture, scar esthetic and superficialization of the implant respectively. The causes are multifactorial, with a greater tendency of association to the surgical technique. When several diagnoses and etiologies coincide in the same patient, the treatment is individualized, requiring the combination of several surgical techniques to achieve an adequate result with respect to the previous deformity.

The most commonly used surgical technique was periareolar mastopexy, implant change, subglandular to submuscular change, and open capsulotomy. In no case was a single procedure found that could be applicable and reproducible for all late post-mastoplasty augmentation deformities. The results of the secondary mastoplasties were mostly good with few complications. (Figure 3).

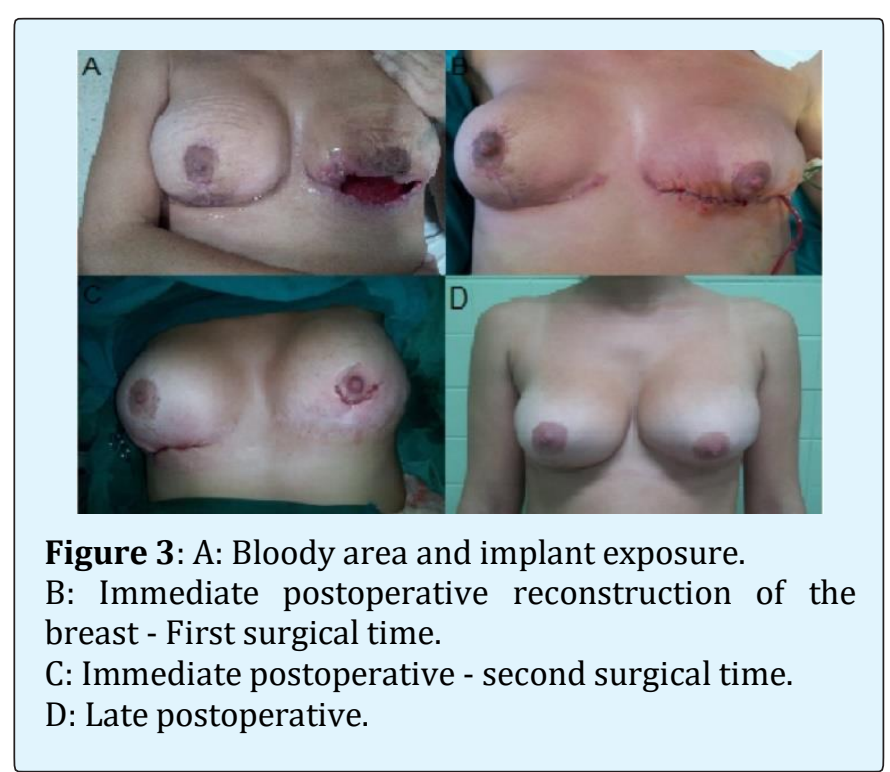

The increase in mastoplasty of primary augmentation implies a consequent increase in secondary mastoplasty. An adequate selection and planning of the procedure is recommended, remembering that in many cases the combination of more than one technique is involved in the same surgical procedure. This study aims to deepen and create solid criteria for successful management and avoid recurrence and nonconformities.

\section{Conclusions}

The surgical treatment of postmastoplasty augmentation deformations must be personalized and the combination of several techniques in the same surgical procedure is generally required to achieve better aesthetic results.

\section{References}

1. Taschen A (2005) Beauty and Cosmetic Surgery. In: Taschen A (Ed.), Plastic surgery. 1st (Edn.). Italy: Taschen, pp: 10-15.

2. Sarwer DB, Spitzer JC (2012) Body image dysmorphic disorder in persons who undergo aesthetic medical treatments. Aesthet Surg J 32(8): 999-1009.

3. Bucky L, Mottura A (2009) Aesthetic Breast Surgery. $1^{\text {st }}($ Edn. $), 1^{\text {st }}$ (Vol.), Philadelphia Saunders: Elsevier.

4. Coiffman F (2008) Mamoplastias de aumento. In: Coiffman F, Vásquez G (Eds.), Cirugía Plástica, Reconstructiva y Estética. $3^{\text {rd }}$ (Edn.), 4th (Vol.), Colombia: AMOLCA, p. 3113-3174. 


\section{International Journal of Transplantation \& Plastic Surgery}

5. Gonzalez FR, Moreno GI, Vaquero PM (2017) Cirugía estética mamaria: aumento, reducción, mastopexia. $2^{\text {nd }}(E d n),. 2^{\text {nd }}($ Vol.), España: Sociedad Españora de Cirugia Plastica, Reparadora y Estetica.

6. Patrick C, Winfield R (2006) Breast Augmentation. In: Mathes (Ed.), Plastic Surgery. 2nd (Edn.), 2nd (Vol.), Philadelphia: Saunders, pp: 1-34.

7. Wang AB, Alexander D (2009) Breast Augmentation. In: Nahabedian M, Evans G (Eds.), Cosmetic and Reconstructive Breast Surgery. Toronto: Elsevier Saunders pp: 119-133.

8. Jewell M (2012) Silicone gel breast implants at 50: the state of the science. Aesthet surg J 32(8): 1031-1034.

9. Spear SL, Jespersen MR (2010) Breast implants: saline or silicone. Aesthet surg J 30(4): 557-570.

10. Dowden R (2011) Discussing the advantages of saline and silicone implants in clinical practice. Aesthet Surg J 31(2):265.

11. Berrocal RM (2014) Las cuatro estaciones de las mamas. Colombia: Impresion Medica.

12. Escudero FJ, Guarch R, Lozano J (2005) Reacción Tisular a las prótesis mamarias. Contractura capsular periprotésica. Anales Sis San Navarra 2(2): 41-53.

13. Karp N (2007) Mastopexy and mastopexy augmentation. In: Thorne C (Ed.), Plastic surgery Grabb - Smith: 6 $6^{\text {th }}$ (Edn.), United States of America: Lippincott williams \& wilkins, pp: 585-592.

14. Slavin S, Greene A (2007) Augmentation mammoplasty and its complications. In: Thorne $\mathrm{R}$ (Ed.), Plastic surgery Grabb - Smith: $6^{\text {th }}$ (Edn.), United States of America: Lippincott williams \& wilkins, pp: 575-584.

15. Colque A, Eisemann ML (2012) Breast augmentation and augmentation-mastopexy with local anesthesia and intravenous sedation. Aesthetic surgery journal 32(3): 303-307.

16. Stanley S, Hoppe I, Ciminello F (2012) Pain control following breast augmentation: a qualitative systeatic review. Aesthet Surg J 32(8): 964-972.

17. Urian L, Suarez L, Rodriguez I, Gallego F (2014) Mamoplastia de aumento: complicaciones y manejo postquirurgico desde fisioterapia. Rev Cien Escol Saud 3(2): 37-45.

18. Jacobson J, Gatti M, Schaffner A, Hill L, Spear S (2012) Effect of incision choice on outcomes in primary breast augmentation. Aesthet Surg J 32(4): 456-462.

19. Bartsich S, Ascherman J, Whittier S, Yao CA, Rohde C (2011) The breast: a clean-contaminated surgical site. Aesthet Surg J 31(7): 802-806.

20. Wiener TC (2013) Betadine and breast implants: an update. Aesthet Surg J 33(4): 615-617.

21. Benito Duque P, De Juan HuelvesA, Cano Rosas M, Díaz E, Elena Sorando E, et al. (2011) A new way to treat the exposed breast implant. Cir Plast Iberolatinoam 37(1): 63-66.

22. Barrantes M, Perez M, Chaparro J (2011) Formacion de hematoma tardío postmamoplastia de aumento. An Med 56(2): 104.

23. Herran F, Lugo I, Menendez N, Trigos I (2010) Seroma tardio despues de mamoplastia de aumento con implantes de silicon. Cir Plast 20(2): 87-92.

24. Rodriguez F (2012) Severe galactorrhea after mammary augmentation with implants. Cir Plast Iberolatinoam 38(2): 169.

25. Avsar D, Aygit A, Benlier E, Top H, Taskinalp O (2010) Anthropometric breast measurement: a study of 385 turkish female students. Aesthetic Surg J 30(1): 4450 .

26. Jatoi I, Kaufmann M, Petit J (2006) Atlas of breast surgery. Germany: Springer.

27. Blount AL, Martin MD, Lineberry KD, Kettaneh N, Alfonso D (2013) Capsular contracture rate in a lowrisk population after primary augmentation mammaplasty. Aesthet Surg J 33(4): 516-521.

28. Tbitblbaum S (2014) Augmetation Mammaplasty: Principles, Techniques, Implant choices and complications. In: Thorne C (Ed.), Grabb and Smith's Plastic Surgery, 7th (Edn.), United States of America: Wolters Kluwer, pp: 565-581.

29. Mofid M (2011) Acellular dermal matrix in cosmetic breast procedures and cápsular contracture. Aesthetic surgery journal 31(7S): 77S-84S. 